\title{
Deconstrucción de las garantías constitucionales de la seguridad social de los informales en Colombia, utopía o realidad.*
}

\section{Deconstruction of the constitutional guarantees of the social security of the informal in Colombia, utopia or reality.}

\author{
Manuel Mauricio Moreno Villamizar
}

\section{Resumen}

El presente artículo de reflexión tiene como objetivo estudiar la realidad de los trabajadores que se encuentran en la economía informal en situación de exclusión, precarización y pobreza, quienes no pueden seguir siendo discriminados del sistema general de seguridad social integral por estar vinculados en el ordenamiento jurídico interno e internacional por los principios rectores de eficiencia, solidaridad y universalidad del sistema, y de esta forma brindar garantías mínimas constitucionales y legales propias del Estado Social de Derecho que busca defender y proteger de derechos inherentes a la

* Artículo de Reflexión.

** Doctorando en Derecho, Universidad Libre, Bogotá, 2018. magíster en Gestión de la Tecnología Educativa, Universidad de Santander, Bucaramanga; especialista en Derecho Laboral y Seguridad Social, Universidad Libre, Bogotá; especialista en Administración de la Informática Educativa, Universidad de Santander, Bucaramanga; abogado, Universidad Cooperativa de CoIombia, Villavicencio; licenciado en Ciencias Religiosas y Éticas, Fundación Universitaria Juan de Castellanos, Tunja; bachiller en Filosofía y Teología, Seminario Mayor de Bucaramanga; Docente de Medio Tiempo, Universidad de la Costa, extensión Villavicencio. 
condición humana. La seguridad social tiene un carácter vinculante y fundamental en el Estado Social de Derecho que contrasta con la realidad, y de forma concreta en el contexto laboral y de la seguridad social por parte de los trabajadores que se encuentran en la economía informal.

La economía informal en Colombia es un reflejo de la injusticia y desigualdad social como consecuencia del fenómeno de la globalización y flexibilización laboral que conduce a una precarización laboral en aumento, al restringir y limitar derechos por parte del Estado con una serie de medidas y política pública excluyente y alienante al otorgar primacía al modelo económico neoliberal, con el amparo del legalismo jurídico imperante. Se elige como referente de investigación el modelo de investigación aplicada al correlacionarse con otras disciplinas del conocimiento y realidades que se articulan con las ciencias sociales, asumiendo un enfoque de carácter iusfilosófico que busca el análisis de las normas jurídicas, su correspondencia o discrepancia frente al conjunto de valores y principios de la sociedad, al determinar como eje central de la investigación la relación que existe entre el derecho y la justicia. La informalidad requiere ser analizada, reconstruida e interpretada desde la filosofía del derecho como deconstrucción al resignificar el derecho laboral y seguridad social como derechos inherentes al hombre.

\section{Palabras clave:}

Dignidad humana, deconstrucción, Estado Social de Derecho, economía informal, legalismo jurídico, política pública, precarización laboral, principios del derecho y seguridad social.

\section{Abstract}

This article of reflection aims to study the reality of workers who are in the informal economy in a situation of exclusion, pre- 
cariousness and poverty, who cannot continue to be discriminated against from the general comprehensive social security system because they are linked in the legal system internal and international by the guiding principles of efficiency, solidarity and universality of the system, and in this way to provide minimum constitutional and legal guarantees of the Social State of Law that seeks to defend and protect rights inherent to the human condition. Social security has a binding and fundamental character in the Social State of Law that contrasts with reality and in a concrete way in the labor and social security context by workers who are in the informal economy.

The informal economy in Colombia is a reflection of social injustice and inequality as a consequence of the phenomenon of globalization and labor flexibility that leads to increasing job insecurity, by restricting and limiting rights by the State with a series of measures and public policy excluding and alienating by granting primacy to the neoliberal economic model under the protection of the prevailing legal legalism. The applied research model is chosen as a research reference when it is correlated with other disciplines of knowledge and realities that are articulated with the social sciences, assuming a legal-philosophical approach that seeks the analysis of legal norms, their correspondence or discrepancy compared to the whole values and principles of society, by determining the relationship between law and justice as the central axis of the investigation. Informality needs to be analyzed, reconstructed and interpreted from the philosophy of law as deconstruction by resignifying labor law and social security as rights inherent to man.

\section{Key words:}

Human dignity, deconstruction, Social State of Law, informal economy, legal legalism, public policy, job insecurity, principles of law and social security. 


\section{Introducción}

El contexto laboral y de la seguridad social se reduce en la actualidad a una situación de expedición de normas jurídicas ${ }^{1}$ para la regulación de derechos fundamentales, que en la práctica se traduce en una simple instrumentalización y enajenación del hombre, denunciado y descrito por Marx en su obra "Manuscritos económicos y filosóficos de 1844", al perderse el real sentido del trabajo como derecho en relación a la dignidad humana, convirtiendo al hombre en una mercancía y ajeno al producto de su trabajo (Marx, 1844, p. 35). Esta situación genera un entorno de precarización laboral como consecuencia del fenómeno de la globalización e implementación de políticas liberales, que son la expresión de un Estado mínimo, que reduce las funciones estatales y protección de derechos individuales, perdiendo el hombre el horizonte y la capacidad de asombro de encontrarse a sí mismo, limitando el mundo jurídico a una simple regulación normativa, aminorando la esencia y efectos de los derechos humanos expresos en el ordenamiento jurídico colombiano a través de los derechos fundamentales que tienen como eje central la dignidad humana y, por ende, desconociendo el fin último de la persona como sujetos de derechos, de acuerdo al planteamiento kantiano.

Se avizora la situación de desprotección en el grupo poblacional que se encuentra ubicado en la economía informal, marginado del sistema de seguridad social integral, reconocido por el ordenamiento jurídico internacional, en primer lugar, a partir de 1948 como derecho humano y, en segundo lugar, en el ordenamiento jurídico

1 Código Sustantivo del Trabajo regula las relaciones laborales; Ley 50 de 1990 introduce reformas al Código Sustantivo de Trabajo; Ley 100 de 1993 crea el sistema de seguridad social integral; Ley 797 y 860 de 2003 regula lo concerniente al sistema general de pensiones; Ley 1562 de 2012 regula el sistema de riesgos laborales; Decreto 1443 de 2014 regula la implementación del sistema de gestión de seguridad y salud en el trabajo; Ley 1751 de 2015 regula la salud como derecho fundamental; Decreto 1072 de 2015 reglamenta el sector trabajo; Decreto 1833 de 2016 recopila normas del sistema general de pensiones; Decreto 780 de 2016 regula salud y protección social. 
interno como derecho fundamental con la Constitución de $1991^{2}$. En el contexto real, el sistema está diseñado a partir de vínculos laborales de las personas que aportan, es decir, aquellos que tienen capacidad de pago, sin ofrecer alternativas a un significativo número de personas que se mantienen en la periferia, como ocurre con los informales, restringiendo el carácter deontológico y teleológico de la Carta Política que garantiza la efectividad de los principios, derechos y deberes, como también la de proteger a todos los residentes del territorio la vida, honra, bienes, creencias y demás derechos y libertades a un simple proyecto programático, que se traduce en una falacia por la ineficacia de los principios constitucionales y legales del sistema general de seguridad social, que están determinados por los principios rectores de eficiencia, universalidad y solidaridad (Constitución Política de Colombia, 1991, art. 48) y reiterados en la Ley 100 de 1993, que incluye, de igual forma, los principios de integralidad, unidad y participación (Congreso de la República de Colombia, 1993, art. 2), con el supuesto de asegurar el cumplimiento de los deberes sociales del Estado.

El derecho no es un producto acabado que se subsume en el formalismo jurídico, legicentrista o simple subsunción de reglas ajenas a la realidad social del hombre calificado por Hart como un vicio que "consiste en una actitud hacia las reglas verbalmente formuladas que procura encubrir y minimizar la necesidad de tal elección, una vez que la regla general ha sido establecida" (Hart, 1998, pág. 161). El derecho debe ser el resultado de un proceso vivo, dinámico, transformador e interpretativo de acuerdo con el contexto actual que se articula al ordenamiento jurídico, pero que requiere de una verdadera deconstrucción a través de los principios como eje central del derecho laboral y la seguridad social. En estos términos, es impor-

2 Declaración Universal de los Derechos Humanos, 10 diciembre de 1947, París, Francia; Constitución Política de Colombia, artículo 48; Ley 516 de 1999, artículo 1 establece la seguridad social como un derecho inalienable del ser humano. La Corte Constitucional SU-057 de 2018 reitera que la seguridad social es un derecho fundamental. 
tante reconocer el alcance del sentido de la palabra deconstrucción, que fue propuesto por el argelino Jacques Derrida (Derrida, 1993, p. 57ss), quien relativiza los conceptos dominantes con un espíritu nihilista, todas aquellas categorías existentes, y desjerarquizando el orden establecido para ser analizado desde otra óptica, que no significa una simple interpretación de la realidad o de los textos, sino una deconstrucción de los mismos, para evitar caer en posiciones dogmáticas, extremistas y totalitarias que solamente imponen modelos de verdad absoluta, homogeneidad o un carácter monológico, que desconoce la realidad o nos aparta de la misma (Derrida, 1989, p. 211ss). La deconstrucción fue también desarrollada por Martin Heidegger en su obra El ser y el tiempo (Heidegger, 1993, p. 33ss), relacionándola con el concepto de destrucción al inducir la búsqueda del carácter ontológico de la realidad, que en el contexto actual se traduce en dar un sentido y significado a las palabras desde el ser y no desde el aspecto kantiano del deber ser, es decir, resignificando el derecho laboral y seguridad social como derechos inherentes al hombre con caracteres de fundamentalidad, irrenunciabilidad y universalidad.

De ahí, la deconstrucción de las garantías constitucionales y legales del sistema de seguridad social, como utopía o realidad, que no puede convertirse en simples postulados programáticos y aspiracional, lo cual se traduce en palabras estériles sin alcanzar el verdadero valor jurídico de aplicabilidad y efectividad concedido por los principios del derecho frente a las decisiones públicas y judiciales que justifican la esencia misma del Estado Social de Derecho, donde no solamente se respeta la equidad y la justicia, sino también la coherencia del derecho en su integridad para evitar reduccionismos jurídicos y posturas contrarias a la misma dignidad humana (Bonorino y Peña, 2006, p. 39).

Los principios, igual que las normas, confieren derechos e imponen obligaciones, y responden a los problemas concretos cuando 
las normas no son suficientes para hallar solución al caso analizado (Dworkin, 1989); por ende, se requiere deconstruir los principios por parte de los poderes públicos como mecanismo para alcanzar una verdadera justicia material, y ser analizada e interpretada desde la filosofía del derecho para resignificar el derecho laboral y la seguridad social y de esta manera garantizar cobertura real a toda la población laboral sin exclusión, como estrategia de formalización del empleo y equilibrio social a partir de la prevalencia de derechos y principios inalienables de la persona sobre el legalismo imperante, en consonancia con las políticas públicas de gobernanza global y globalización del derecho internacional.

Se puede presumir que la situación de la economía informal frente al derecho laboral y seguridad social ha sido un problema jurídico resuelto a través del precedente constitucional y judicial, que ordenan a las autoridades administrativas la reubicación y capacitación de esta población excluida del sistema económico imperante, convirtiéndola en sujetos de especial protección por su condición de debilidad manifiesta, tal como lo refiere la Corte Constitucional en su control abstracto:

6.1. A pesar de que la Constitución establece que Colombia está organizada como Estado social de derecho $\left(\right.$ art. $1^{\circ}$ ); que el Estado debe proteger especialmente aquellas personas que por su condición económica, física o mental se encuentren en circunstancias de debilidad manifiesta (art. 13); que el trabajo tiene una cuádruple naturaleza porque es un valor (preámbulo), un principio (arts. $1^{\circ}$ y 53), un derecho (art. 25) y una obligación (art. 25), que se debe garantizar a toda la población colombiana en condiciones dignas y justas; que el Estado debe propiciar la ubicación laboral de las personas en edad de trabajar y garantizar a los minusválidos el derecho a un trabajo acorde con sus condiciones (art. 54); y que el Estado intervendrá para dar pleno empleo a las personas y asegurar, de manera progresiva, que todas las personas, en particular las de menores ingresos, tengan acceso efectivo al conjunto de los bienes y servicios básicos (art. 334); resulta evidente que el desempleo, la falta de oportunidades, el cierre de empresas y las desigualdades sociales siguen presentes y se cuentan entre las causas que llevan a los ciudadanos a 
emplear los recursos necesarios para sobrevivir como la venta informal con utilización del espacio público (C-211, 2017).

No se puede desconocer el apoyo que brindan las entidades territoriales con la entrega de beneficios e instrumentos de trabajo para incentivar la formalización laboral, como por ejemplo, el reemplazo de las zorras por moto cargueros, pero con el agravante de seguir considerando el sistema de seguridad social integral como un derecho accesorio o privilegio para aquellos que solamente aportan al sistema, que a simple vista suena una falacia que se desvirtúa con el argumento de brindar cobertura a toda la población, que no se presenta al ser confrontado con la realidad, porque las personas que no tienen capacidad de pago reciben únicamente beneficios en salud a través del régimen subsidiado con las prestaciones asistenciales ajenas a las prestaciones económicas, que las reciben quienes aportan al sistema en el régimen contributivo a través de las incapacidades médicas, licencia de maternidad, licencia de paternidad y licencia de aborto, y qué decir, de igual forma, de quienes se mantienen excluidos del sistema general de riesgos laborales frente a las contingencias de enfermedad laboral o accidente de trabajo y del sistema general de pensiones por no aportar al sistema.

El ordenamiento jurídico colombiano en su carácter teleológico y deontológico busca mejorar las condiciones de vida y cubrir las contingencias del hombre frente a la enfermedad, pensión, invalidez y muerte a través de la cobertura del sistema general de seguridad social integral, el cual está compuesto por el sistema general de seguridad social en salud, sistema general de riesgos laborales, el sistema general de pensiones y los servicios sociales complementarios ${ }^{3}$; cubre integralmente las prestaciones asistenciales y económicas siempre y cuando, o como conditio sine qua non, aporten al sistema, indepen-

3 Ley 100 de 1993, artículo 8: "Conformación del sistema de seguridad social integral. El Sistema de Seguridad Social Integral es el conjunto armónico de entidades públicas y privadas, normas y procedimientos y está conformado por los regímenes generales establecidos para pensiones, salud, riesgos profesionales y los servicios sociales complementarios que se definen en la presente ley". 
dientemente del vínculo o relación laboral, desconociendo la realidad de aquellos que se mantienen en la economía informal que, de acuerdo con el Departamento Administrativo Nacional de Estadística (DANE), del trimestre de noviembre de 2019 al mes de enero de 2020 representan el 47,7\% de la población laboral informal de las trece principales ciudades y un $46,6 \%$ de las siguientes veintitrés ciudades (DANE, 2020). Es un deber del Estado colombiano brindar oportunidades de empleo digno y justo, que fomente la formalización laboral con capacitaciones y reinserción social a aquella parte de la población marginada, buscando reconocer el carácter vinculante de la dignidad humana frente al legalismo jurídico imperante, sin desconocer derechos y principios del hombre; lo que comienza con la cobertura y protección al sistema de seguridad social integral.

La estructura del plan de trabajo parte del problema jurídico que describe la situación que afrontan los trabajadores que se encuentran en la economía informal, que es analizado en el contexto socio-jurídico de la informalidad y confrontado por el valor de los principios rectores en materia de seguridad social para llegar a una deconstrucción del derecho y de la seguridad social que no puede convertirse en una situación utópica, sino real y efectiva del derecho que tiene como eje central el reconocimiento de la condición humana.

Es importante reconocer los elementos esenciales de la política pública del Estado Social de Derecho, el cual está direccionado al cumplimiento efectivo de los principios y derechos fundamentales en la promoción y reconocimiento de la dignidad humana, que comienzan a garantizarse a través de la cobertura al sistema general de seguridad social integral a toda la población, partiendo de los principios rectores de la eficiencia, solidaridad y universalidad del sistema. Por consiguiente, ¿́cómo se garantiza el derecho al acceso efectivo al sistema general de seguridad social integral de toda la población 
laboral, especialmente de aquellos que se mantienen en la economía informal?

La estructura del ordenamiento jurídico interno parte de la misma Constitución Política de Colombia y de tratados internacionales que han sido ratificados por el Congreso, que reivindica los derechos humanos y han sido positivizados como derechos fundamentales propios de un Estado Social Democrático al establecer la división de poderes y brindar garantías básicas al conglomerado social, que lamentablemente contrasta con la realidad jurídica y social de la población laboral que se encuentran en la informalidad por el aparente abandono y omisión por parte del Estado en la cobertura al sistema general de seguridad social integral frente a las contingencias humanas que se ven aminoradas en la eficacia real de los principios rectores constitucionales y legales del sistema que los cubre a través de las prestaciones asistenciales y económicas. La seguridad social está estructurada para beneficiar y proteger a la población frente a todas las eventualidades propias del hombre, guardando una estrecha relación con la misma dignidad humana, que constituye el principio fundante de todo Estado Social de Derecho. Hay que aclarar que la cobertura integral en salud, pensión y riesgos laborales la adquieren única y exclusivamente aquellas personas que tienen capacidad de pago por mantener un vínculo contractual vigente, ya sea de carácter laboral, civil, comercial, administrativo o como independiente, excluyendo a una parte de la población que no se encuentra en estas categorías, es decir, aquellos que no tienen capacidad de pago, porque solamente son protegidos por el sistema de seguridad social salud a través del régimen subsidiado, pero no gozan de cobertura en materia de pensión y riesgos laborales.

No se puede desconocer cómo el modelo de seguridad social responde a un proceso histórico que se fue desarrollando de una manera lenta y continua para convertirse en un derecho humano (ONU, 1948), e implantado en la realidad colombiana como un 
servicio público de carácter obligatorio en la Constitución Política de Colombia (Constitución Política de Colombia, 1991. Art. 48) y reglada en la Ley 100 de 1993 a través de los principios de eficiencia, universalidad, solidaridad, integralidad, unidad y participación, brindando un carácter vinculante y obligatorio a este derecho como servicio público esencial. Es interesante la forma como la Corte Constitucional define la esencialidad de un servicio público:

cuando las actividades que lo conforman contribuyen de modo directo y concreto a la protección de bienes o a la satisfacción de intereses o a la realización de valores, ligados con el respeto, vigencia, ejercicio y efectividad de los derechos y libertades fundamentales, ello es así, en razón de la preeminencia que se reconoce a los derechos fundamentales de la persona y de las garantías dispuestas para su amparo, con el fin de asegurar su respeto y efectividad. (C-450, 1995)

El ordenamiento jurídico interno es claro y en consonancia con los tratados internacionales, pero frente al fenómeno de la globalización que impone un modelo neoliberal induce al Estado colombiano a implementar políticas públicas mínimas en materia laboral y de la seguridad social que promueve una desregulación de los derechos irrenunciables del hombre, como ocurre con la población laboral que se mantiene en la informalidad. Se colige, entonces, cómo la realidad de la informalidad en la cobertura al sistema general de seguridad social no responde al objetivo central de protección de la dignidad humana, a pesar de estar instituido y con una connotación de derecho fundamental, que se considera en la práctica letra muerta, porque el ordenamiento jurídico no está en armonía con los preceptos fundamentales de la persona. Frente a esta situación, el derecho debe ser asumido de una forma integral, tal como lo expone Ronald Dworkin (1989), donde los derechos de las personas prevalecen sobre el legalismo jurídico sin vulnerar derechos inherentes e irrenunciables y de esta manera comenzar a reconocer los derechos en serio. El derecho debe aplicarse e interpretarse a través de los principios para resolver los problemas jurídicos actuales vigentes, 
como ocurre con aquella parte de la población que se encuentran en la informalidad que exige de los poderes públicos una verdadera articulación y deconstrucción de los derechos y principios que sirvan de fundamento y reconocimiento de la dignidad humana.

\begin{abstract}
Se definen los trabajadores de la economía informal como aquellos
trabajadores que no están cubiertos por la legislación laboral y, por lo tanto, no están sujetos a las reglas formales del mundo del trabajo ni a la justicia laboral correspondiente; no cotizan a la seguridad social y, por consiguiente, no son parte del Estado de bienestar, ni del pacto social que debe caracterizar a las sociedades modernas; en su mayoría tienen empleos de baja productividad y, en consecuencia, sus ingresos son bajos. (Salazar-Xirinachs y Chacaltana, 2018, p. 15)
\end{abstract}

Esto es una situación jurídica que genera desigualdad, injusticia e inequidad anteponiendo el legalismo jurídico sobre la misma dignidad humana, desconociendo, por ende, derechos inalienables de la persona, siendo necesario la aplicación e interpretación adecuada de los principios en el derecho con el fin de dar el respectivo peso al caso concreto, sin abandonar el principio rector a favor de la persona o pro-homine, que se traduce en el mismo reconocimiento de la dignidad humana (T-085, 2012), desvelando, entonces, la esencia del derecho que se balancea en situaciones y hechos jurídicos concretos a través de la razonabilidad.

El artículo busca vincular el carácter trilemático principista de la eficiencia, solidaridad y universalidad del sistema de seguridad social integral frente a la informalidad en el territorio colombiano que desconoce garantías mínimas constitucionales y legales que brinda el Estado Social de Derecho en la defensa y protección de derechos inherentes a la condición humana. Se interpreta la realidad de la informalidad dentro de la estructura estatal sin desconocer el modelo de Estado que se fundamenta en principios y valores, donde los primeros son normas jurídicas para el presente con un carácter deontológico, mientras que los segundos son fines jurídicos para el futuro 
con un carácter axiológico (T-406, 1992), enfatizando en la necesidad de deconstruir los principios rectores y garantías de la seguridad social como derecho irrenunciable y universal que se reducen a simples expresiones jurídicas sin poder vinculante, que no cuentan con un campo de aplicación y efectividad en el ordenamiento jurídico, demandando una exigencia de ser analizada, reconstruida e interpretada desde la filosofía del derecho y de esta forma resignificando el derecho laboral y seguridad social como un derecho inherente al hombre.

\section{El contexto socio-jurídico del fenómeno de la informalidad:} Colombia como Estado Social de Derecho está llamada a garantizar la efectividad de los derechos fundamentales de toda la población, especialmente de aquellas personas en debilidad manifiesta y que se ubican en la periferia, marginalidad y exclusión por factores sociales, económicos y políticos, que deben ser protegidas e incluidas en la política pública gubernamental a través del reconocimiento de derechos, libertades e igualdades a toda la comunidad, promoviendo de forma preferente los derechos de los grupos minoritarios que se mantienen en situaciones de injusticia e inequidad como ocurre con la población que se ubica en la economía informal. El modelo del Estado colombiano sigue la idea de que:

Una mirada al hombre bajo la óptica del Estado Social de Derecho impone no solo hacerlo desde el contexto legal, sino también desde el ámbito natural, esto es, que además de necesidades materiales provenientes del ejercicio de su existencia, el ser humano también las tiene de tipo emocional, cultural, espiritual, ideológico, etc., que no por abstractas tienen menor valor que las primeras con lo que puede acuñar el denominado principio de la "seguridad humana". (Cabrera, 2018, p. 5)

Por eso, demanda garantías mínimas de protección a la condición humana, que en su deber ser como modelo de bienestar debería ser una garantía de cobertura integral en el sistema general de seguridad social, y de manera concreta para el sector informal, para 
constituir una estrategia de formalización del empleo, asegurando protección a todas las personas, traspasando metafísicamente el legalismo jurídico imperante, es decir, superando la simple subsunción de reglas o normas al reconocer de forma integral el ordenamiento jurídico como una construcción de derechos, principios y valores, en consonancia con los tratados internacionales que protegen los derechos humanos. Así, por ejemplo, el artículo 22 de la Declaración Universal de Derechos Humanos que establece que "Toda persona, como miembro de la sociedad, tiene derecho a la seguridad social, y a obtener, mediante el esfuerzo nacional y la cooperación internacional, habida cuenta de la organización y los recursos de cada Estado, la satisfacción de los derechos económicos, sociales y culturales, indispensables a su dignidad y al libre desarrollo de su personalidad"; el artículo 16 de la Declaración Americana de los Derechos de la Persona al afirmar que "Toda persona tiene derecho a la seguridad social que le proteja contra las consecuencias de la desocupación, de la vejez y de la incapacidad que, proveniente de cualquier otra causa ajena a su voluntad, la imposibilite física o mentalmente para obtener los medios de subsistencia”; el artículo 9 del Pacto Internacional de Derechos Sociales y Culturales que establece que "Los Estados Partes en el presente Pacto reconocen el derecho de toda persona a la seguridad social, incluso al seguro social", como también el artículo 9 del Protocolo Adicional a la Convención Americana sobre Derechos Humanos en Materia de Derechos Económicos, Sociales y Culturales que determina que "Toda persona tiene derecho a la seguridad social que la proteja contra las consecuencias de la vejez y de la incapacidad que la imposibilite física o mentalmente para obtener los medios para llevar una vida digna y decorosa”. De igual forma, el Código Iberoamericano de la Seguridad Social, aprobado por la ley 516 de 1999, en el artículo 1, reconoce a la Seguridad Social como un derecho inalienable del ser humano.

La población informal se mantiene al margen del sistema económico imperante que los excluye y se visualiza por ejemplo en las polí- 
ticas públicas ejercidas por las entidades territoriales por medio de la secretaria del espacio público y Policía Nacional a través del control físico, dando prevalencia al espacio público con el argumento de ser derechos imprescriptibles, inalienables e inembargable (Constitución Política de Colombia, 1991, art. 63), justificando de esta forma la premisa legal de la prevalencia del interés general sobre el interés particular, generando, entonces, una tensión social y jurídica entre las partes como también un choque en el peso o balanceo de derechos y principios mínimos que debe brindar el Estado.

El poder ejecutivo cree que el problema de la economía informal se resuelve con las políticas neoliberales, que en realidad incentivan condiciones de precarización, tercerización y desprotección de garantías mínimas laborales y de la seguridad social; como ocurre en las declaraciones de la anterior Ministra de Trabajo Alicia Arango, quien expuso como alternativa para la formalización laboral el trabajo por horas, palabras que fueron de igual forma reiteradas por el Presidente de la República (Duque, 2020), que son contrarias a la realidad, porque los mismos informes trimestrales que reporta el Departamento Administrativo Nacional de Estadística (DANE) denota un alto índice de informalidad y exclusión, guardando congruencia con los reportes del Departamento Nacional de Planeación (DNP). Estas situaciones fácticas se argumentarán más adelante en el título de la deconstrucción del derecho y de la seguridad social ${ }^{4}$. De igual forma, reprocha el mismo Procurador General de la Nación, quien expresó que "a la gente hay que oírla, a la calle hay que oírla” (Carrillo, 2020), al constatarse cómo casi la mitad de la población laboral en Colombia (el 47,6 \%) se mantienen en la informalidad y ajenos al sistema de seguridad social integral, de acuerdo con el último reporte trimestral del DANE año 2019 (DANE, 2020).

4 Decreto 1174 de 2020, por el cual reglamenta el Piso de Protección Social para personas que devengan menos de un salario mínimo. Artículo 2.2.13.14.1.3. Ámbito de aplicación. Serán vinculados al Piso de Protección Social: 1. Vinculados obligatoriamente: 1.1. Las personas que tengan uno 0 varios vínculos laborales por tiempo parcial y que en virtud de ello reciban un ingreso total mensual inferior un salario mínimo legal mensual vigente. 
Hay que tener presente que esta la entidad pública es responsable de estudiar, analizar y reportar las estadísticas de empleo, desempleo e informalidad, describiendo cómo se encuentra una gran parte del consenso de trabajadores excluidos de las garantías básicas del derecho al trabajo y de la seguridad social y sin mediar un balanceo de principios constitucionales y legales de protección y reconocimiento de la dignidad humana de aquellas personas que se mantienen en situaciones de informalidad.

El modelo económico imperante promueve una serie de medidas de precarización laboral y una reducida intervención estatal que son fijadas por una política pública de gobernanza global (FMI, 2019), que se desvela en la instrumentalización del hombre a través del trabajo al convertirlo en un simple objeto que produce insumos, generando en la realidad actual una situación de cosificación y alienación, desnaturalizando el real fin del trabajo como factor determinante de la dignidad humana e ignorando el planteamiento kantiano de reconocimiento de la persona no como un medio, sino como un fin último (Kant, 1921). Es así que la realidad de la economía informal requiere de un verdadero estudio y análisis de las condiciones laborales de esta parte de la población, como ocurre con la Ley 1955 de 2019 que plasma el Plan Nacional de Desarrollo, al estructurar en tres pilares el cuatrienio del gobierno actual, como lo son la formación de competencias pertinentes y calidad para el empleo, impulsar el servicio público de empleo e incentivar el emprendimiento y el fortalecimiento empresarial (Congreso de la República de Colombia, 2019). Esta realidad requiere de una deconstrucción de paradigmas y modelos establecidos para retomar la esencia real y material del trabajo y de esta manera evitar una continua vulneración de derechos y principios rectores básicos del trabajo y de la seguridad social con el reconocimiento de los derechos inherentes de la persona, guardando coherencia con los principios del derecho a través de la ponderación de los mismos. La ponderación es el camino de reconocimiento de derechos y principios (Alexy, 2002) que 
busca una real materialización de la justicia y defensa de la condición humana. De ahí que la Corte Constitucional llama la atención a todos los poderes públicos y comunidad en general de no perder el horizonte del Estado Social de Derecho:

4.8. Los seres humanos no son objetos o instrumentos, que solo sean valiosos en la medida de su utilidad a los fines individuales o económicos de los demás. Las personas tienen un valor en sí mismas, y al experimentar una afectación de salud no pueden ser tratadas como las mercancías o las cosas, que se desechan ante la presentación de un "desperfecto" o "problema funcional". Un fundamento del Estado constitucional es "el respeto de la dignidad humana” (CP art 1), y la Constitución establece que el trabajo, "en todas sus modalidades debe realizarse en condiciones dignas y justas” (CP art 25). Estas previsiones impiden que en el trabajo las personas sean degradadas a la condición exclusiva de instrumentos. (SU 049, 2017)

La actitud pasiva de las autoridades judiciales, quienes se limitan a garantizar protección de derechos formales, pero no sustanciales o reales al desconocer la esencia misma del Estado Social Democrático de Derecho, que radica en la misma persona y dignidad humana, porque el precedente, $\mathrm{y}$ de forma concreta el precedente constitucional, aborda el fenómeno jurídico de la informalidad brindando aparentes soluciones, pero que en ultimas están desconectadas con los fines esenciales del Estado, sin ahondar en las decisiones o resolver el verdadero problema de cobertura al sistema general de seguridad social integral de la población informal, y que simplemente se reduce en una reubicación, alternativas de trabajo y respeto del principio de confianza legítima con el argumento de

un establecimiento público de ese municipio, cuya función es definir, diseñar y ejecutar programas dirigidos a otorgar alternativas para los sectores de la economía informal a través de la formación de capital humano, el acceso al crédito, la inserción en los mercados de bienes y servicios y la reubicación de las actividades comerciales o de servicios del sector de la economía informal y que está dotado de personería jurídica, autonomía administrativa y presupuestal (el IPES), sí vulneran los derechos al trabajo, al mínimo vital, a la vida digna y al debido proceso de una trabajadora informal que a su vez 
es madre cabeza de familia y miembro de una comunidad indígena, cuando proceden con la ejecución de una diligencia policiva de desalojo y limitan su actuación a mantener su inscripción en un registro de vendedores informales, argumentando el cumplimiento de un deber constitucional y legal, a pesar de que (i) dicha actividad es su única fuente de ingresos, (ii) ha estado inscrita como vendedora informal por más de doce años, y (iii) no le han ofrecido ningún programa de reubicación. (T-067, 2017)

En estos términos, el precedente constitucional en ejercicio del control abstracto determinó cómo el Estado tiene el deber de velar por la integridad del espacio público al imponer una carga a la administración, pero sin desconocer el eje central del derecho, que es la misma persona:

(...) favor del respeto de estas áreas y de esta manera evitar que sufran menoscabo en los aspectos físico, social, cultural, urbanístico e incluso jurídico, para que la comunidad pueda desarrollar actividades lúdicas, recreacionales e incluso para valerse de ellas con el fin de transportarse empleando las zonas habilitadas para este propósito, en aras de una convivencia pacífica. No obstante (...) cabe brindar a las personas que, amparadas en el principio de buena fe, se han dedicado a actividades informales en zonas consideradas como espacio público y frente a las cuales, al momento de aplicar las medidas correctivas, se tendrán en cuenta los principios de proporcionalidad y razonabilidad, en los términos de la jurisprudencia constitucional. (C-211, 2017)

Estas ambigüedades fácticas jurídicas se reflejan, de igual forma, en el desinterés de la población que se mantiene en la economía informal respecto a la afiliación al sistema general de seguridad social integral a través del régimen contributivo. En la mayoría de los casos este grupo poblacional desconoce los beneficios que brinda el sistema por medio de las prestaciones asistenciales y económicas cuando se encuentran cubiertos como contribuyentes y no como beneficiarios o régimen subsidiado.

Otros, en cambio, no contribuyen en aportes al sistema integral porque no alcanzan a obtener el mínimo vital por la situación marginal que afrontan en el diario vivir, contrarias a la misma dignidad 
humana. El legicentrismo jurídico colombiano no responde al caso concreto permitiendo vulneración y desprotección de derechos inalienables de la población informal sin políticas públicas de inserción social y laboral ni subvenciones o estímulos que incentiven la formalidad. Se desvelan, entonces, falencias en las políticas públicas que direccionan el Estado Social de Derecho que no son coherentes en las decisiones legislativas, administrativas y judiciales de formalización y protección laboral, con fines de garantizar cobertura al sistema y fortalecer de esta manera condiciones laborales dignas y justas convirtiéndose en una simple utopía el modelo de seguridad social. En estos términos, en el primer centenario de la OIT, el presidente de la República de Colombia, Iván Duque Márquez, manifestó las consecuencias de la informalidad genera grandes desafíos para el mundo laboral:

El informe sobre el futuro del empleo nos permite a todos entender que el reto de la informalidad es grande, que el reto de la informalidad exige que tengamos los mejores instrumentos para que nuestras sociedades, la calidad del empleo vaya acompañada del ahorro para la protección de la vejez y por supuesto de la mayor cobertura de la seguridad social. (OIT, 2019)

Surge la necesidad de deconstruir conceptos jurídicos fundamentales desde la perspectiva de Martin Heidegger (1993), argumentando el carácter ontológico de la realidad, es decir, retomando el real valor de la seguridad social como derecho inherente del hombre con un carácter irrenunciable y universal. De ahí la deconstrucción de las garantías constitucionales y legales de la seguridad social que no puede convertirse en una simple literalidad de la norma o formalismo jurídico; un sofisma o juego de palabras que no trasciende el sentido literal o semántico de la norma o un simple monólogo jurídico reflejado en el autoritarismo mayoritario que representa una clase política o social, porque una verdadera deconstrucción jurídica demanda una resignificación del derecho al romper los estereotipos establecidos para alcanzar una real aplicabilidad y efectividad de derechos y garantías inherente de la persona en el ordenamiento 
jurídico. Por esta razón, la urgencia de deconstruir y comprender el alcance de la palabra de la dignidad humana.

Como sujeto central y último del derecho se materializa en la cobertura al sistema de seguridad social a través de la salud, riesgos laborales y pensión de todos sus asociados sin ninguna clase de reduccionismo o restricciones por factores económicos o sociales, porque el argumento reside en la tesis de reivindicar el verdadero alcance de los principios como eje central del derecho laboral y seguridad social que traspasa los poderes del público al integrar el ordenamiento jurídico interno e internacional en defensa de la condición humana, especialmente de los más desprotegidos y marginados por el sistema imperante. El poder judicial, y de manera concreta el precedente constitucional, ha superado la primacía legislativa a través de los principios resolviendo conflictos jurídicos laborales y de la seguridad social, representando el carácter iusfundamental de los mismos.

Se debe superar el legicentrismo que declara el imperio de la ley como fuente por excelencia del derecho, retomando la primacía de derechos inalienables de la persona sobre el legalismo jurídico (Constitución Política de Colombia, 1991, art. 5), rechazando posiciones utilitaristas y pragmáticas que argumentan un beneficio para las mayorías y con connotación de interés general para comenzar a reconocer el derecho como integridad que significa igualdad y libertad para todos en el sentido en el que las autoridades públicas deben regirse por un conjunto de estándares que sea en principio aplicable a la comunidad sin exclusión (Dworkin, 2007, p. 195). De esta manera lograr pensar en las minorías que se reflejan en el sector de la informalidad para deconstruir el derecho a través de la argumentación donde las decisiones que toman las autoridades deben estar acordes y en consonancia con los derechos humanos expresos en la Constitución, independientemente del grado generacional o categorización de primera, segunda, tercera o cuarta generación y de ma- 
nera concreta la seguridad social por ser un servicio público esencial, obligatorio y fundamental que es inherente a la condición humana.

La Carta Magna de Colombia está guiada por principios estándares inherentes al hombre, que trascienden el carácter normativo, sobrepasando incluso argumentos políticos y jurídicos para responder las situaciones de inequidad e injusticia social, que son contrarias a la misma dignidad humana que discrepan con los verdaderos fines del Estado de servir a la comunidad, promover y garantizar la efectividad de los principios, derechos y obligaciones de todos los residentes en el territorio colombiano, facultando a la máxima autoridad en materia constitucional en ser interprete de la misma constitución eligiendo por preferencia "la moralidad política" como herramienta para la argumentación y justificación de sus decisiones judiciales (Dworkin, 2007, p. 257). El precedente y de forma puntual, la Corte Constitucional de forma prevalente tanto en el ejercicio del control concreto como abstracto de constitucionalidad asume el nuevo rumbo del derecho de no concebirlo solo como un conjunto de normas y reglas, sino también como un conjunto de principios, que ponderan la argumentación e interpretación del derecho, que no puede seguir tolerando la vulneración y desprotección de derechos de la población que se ubica en la economía informal frente a la cobertura al sistema de seguridad social, por ser un derecho fundamental (T-039, 2017), guardando coherencia y articulación con las garantías mínimas e igualitarias de toda la población como Estado Social de Derecho. La seguridad social es un derecho y un principio fundamental que se debe plasmar en la realidad.

La realidad laboral en el territorio colombiano se caracteriza por un alto nivel de informalidad (OIT, 2016), desvelando condiciones de marginación al mantener una gran parte de la población que no tienen una vinculación contractual aislados de garantías y principios mínimos rectores del derecho laboral y seguridad social que están expresos en la misma Carta Política (Constitución Política de 
Colombia, 1991, art. 53) y plasmados de forma trilemática en su carácter teleológico, deontológico y axiológico que no pueden convertirse en simples ideales o valores altruistas utópicos por parte del Estado, sino concretarse a través del reconocimiento de la dignidad humana. Este tipo informal laboral ha sido debatido a nivel internacional por la Organización Internacional del Trabajo, que reconoce la imperante necesidad de dar respuesta a este fenómeno jurídico a través de la Recomendación número 204 al describir la transición de la economía informal a la economía formal, demandando una serie de acciones por parte de los poderes públicos, como la promoción de políticas macroeconómicas a favor del trabajo, generación de empleos decentes, seguridad social y otras políticas sociales, recomendando a todos los Estados miembros dar el paso de transición de la informalidad a la formalidad

Reconociendo que la alta incidencia de la economía informal, en todos sus aspectos, representa un importante obstáculo para los derechos de los trabajadores, con inclusión de los principios y derechos fundamentales en el trabajo, así como para la protección social, las condiciones de trabajo decente, el desarrollo inclusivo y el Estado de derecho, y tiene consecuencias negativas para el desarrollo de empresas sostenibles, los ingresos públicos y el ámbito de actuación de los gobiernos, en particular por lo que se refiere a las políticas económicas, sociales y ambientales, así como para la solidez de las instituciones y la competencia leal en los mercados nacionales e internacionales;

Reconociendo que la mayoría de las personas que se incorporan a la economía informal no lo hacen por elección, sino como consecuencia de la falta de oportunidades en la economía formal y por carecer de otros medios de sustento;

Recordando que los déficits de trabajo decente - la denegación de los derechos en el trabajo, la falta de suficientes oportunidades de empleo de calidad, una protección social inadecuada y la ausencia de diálogo social— son más pronunciados en la economía informal;

Reconociendo que la informalidad obedece a múltiples causas, incluidas las cuestiones estructurales y de gobernanza, y que, en un contexto de diálogo social, las políticas públicas pueden acelerar el proceso de transición a la economía formal. (OIT, 2015) 
Se desvela, entonces, cómo la realidad de los trabajadores que se encuentran en la economía informal en el ordenamiento interno no responde a los problemas jurídicos relevantes en materia laboral y seguridad social, manteniéndose en la posición monista del formalismo, desconociendo el carácter dinámico del derecho para la resolución del conflicto, donde no solo la actividad laboral subordinada está protegida por el ordenamiento jurídico interno e internacional, sino toda clase de vinculación laboral, donde los principios trasciende la realidad de la norma. Son los derechos individuales logros políticos alcanzados en el devenir histórico del hombre, como triunfos que se deben proteger, desvaneciendo la idea de seguir creyendo que los jueces están limitados en aplicar las normas existentes sin ninguna posibilidad de argumentar jurídica y políticamente la realidad al caso concreto (Dworkin, 2012, p. 132ss). La autoridad pública justifica la garantía y protección en seguridad social a toda la población a través del marco legislativo, expreso básicamente en la Ley 100 (Congreso de la República de Colombia, 1993) y demás normas legales y reglamentarias, que confrontadas con la realidad no responden al problema jurídico de marginación que viven las personas que se encuentran en el sector de la informalidad, porque el sistema está diseñado en proteger integralmente aquellas personas que tienen capacidad de pago a través de las prestaciones asistenciales y económicas que brinda el sistema, reiterándose, entonces, cómo los informales se mantiene al margen de la seguridad social al no cotizar y aportar al sistema.

El valor de los principios rectores en materia de seguridad social: El Estado Colombiano, como Estado Social de Derecho, en su deber ser está llamado a garantizar la promoción y prevención de las contingencias propias del hombre en la cobertura al sistema general de seguridad social integral, como estrategia de formalización del empleo y equilibrio social en el campo laboral desde los principios constitucionales y legales de efectividad, solidaridad y universalidad, en el contexto de que no solamente la actividad laboral subordinada 
e independiente, sino cualquiera sea la naturaleza de la relación laboral, sin distinción ni exclusión, por el hecho de ser un derecho humano universal que protege derechos fundamentales como el trabajo, dignidad humana y seguridad social, con el reconocimiento de los principios propios de la persona sobre el legalismo jurídico imperante que desconoce la dignidad humana, principio rector de un Estado Social de Derecho, prescrito en la ley 100 de 1993, que reconoce como lineamientos claros la eficiencia, universalidad, solidaridad, integralidad, unidad y participación del sistema. Se requiere del diseño e implementación de políticas públicas incluyentes de sectores que han sido marginados a lo largo de la historia comenzando con la deconstrucción de los principios rectores de la seguridad social.

La Carta Política en el artículo 48 determina el carácter trilemático principista del sistema de seguridad social integral expresos en la eficiencia, solidaridad y universalidad. El principio de eficiencia tiene una estrecha relación con los otros dos principios rectores de la seguridad social al garantizar los mínimos recursos para asegurar la existencia digna de todos los hombres, implicando el aprovechamiento de los recursos disponibles y cobertura frente a las necesidades y contingencias del hombre relacionando la eficiencia con los valores, principios y derechos fundamentales. La seguridad social no puede ser concebida en una simple relación mercantil o política de mercado, que fluye en el ámbito de la oferta y la demanda frente al uso de los recursos, pues se está hablando de un derecho irrenunciable, fundamental y obligatorio, como también categorizado como un servicio público esencial. La Carta Política determina que los servicios públicos son inherentes a la finalidad social del Estado en aras de proteger los intereses de todas las personas afiliadas al sistema de seguridad social ${ }^{5}$ y que se deben garantizar de forma continua para preservar un nivel de vida digno. El legislador, por ejemplo, definió el principio de eficiencia como "la mejor utilización social y econó-

5 Constitución Política de Colombia. Artículo 365 y 366: Finalidad social del Estado y servicios públicos. 
mica de los recursos administrativos, técnicos y financieros disponibles para que los beneficios a que da derecho la seguridad social sean prestados en forma adecuada, oportuna y suficiente" (Ley 100 de 1993, artículo 2, literal a). La Corte Constitucional en su análisis de control constitucional abstracto define la eficiencia como:

(...) una relación entre insumos y resultados en la producción de bienes y servicios. La anterior relación puede medirse en términos físicos (eficiencia técnica) o en términos de costo (eficiencia económica). Por el contrario, un concepto de eficiencia distributiva tomará en consideración el bienestar del consumidor o usuario de un servicio, es decir, considerará la asignación de recursos para efectos de producir la combinación de bienes y servicios, que mejor satisfaga la demanda de los consumidores.

Así las cosas, en pocas palabras, la eficiencia técnica consiste en un adecuado aprovechamiento de los recursos disponibles; en tanto que la eficiencia económica supone que una empresa persigue el objetivo de minimizar costos, mediante la elección de insumos y productos técnicamente eficientes.

Ahora bien, el concepto de eficiencia en el sistema de seguridad social resulta ser mucho más amplio que las simples eficacias técnica y económica, por cuanto involucra la prestación de un servicio público esencial, como lo es la salud, la cual a su vez es un derecho constitucional y está interrelacionada con otros valores, principios y derechos fundamentales. De igual forma, esta Corporación ha sostenido que en materia de seguridad social el concepto de "rentabilidad financiera debe ser interpretado no de manera aislada, sino en armonía con los principios superiores previstos en los artículos 48 y 49 constitucionales en relación con el sistema de seguridad social en salud. También en sede de amparo, en numerosas ocasiones el juez constitucional se ha referido al concepto de eficiencia en la prestación del servicio de salud poniendo de manifiesto que trasciende a los criterios meramente económicos.

En suma, el examen que debe adelantar la Corte en relación con la medida no puede soportarse en términos de mera eficacia técnica o económica, por cuanto, se insiste, la prestación del servicio de salud en Colombia no puede ser entendido como un simple "mercado de la salud", regido por las leyes de la oferta y la demanda. La garantía de los derechos económicos, sociales y culturales no depende de criterios de simple utilidad o provecho económico particulares. (C-1041, 2007) 
El principio de solidaridad es uno de los estándares fundamentales del Estado Social de Derecho, expreso en los artículos 1, 48, 49 y 95 de la Constitución Política de Colombia, propia de la naturaleza humana y, por lo tanto, inherente a ella. Al determinarse en el artículo 1 de la Carta política el modelo de Estado Social de Derecho se señala como debe ser una disposición efectiva de los derechos esenciales de toda la población nacional de ayuda y socorro mutuo entre las personas y generaciones. Es uno de los principios orientadores de la seguridad social que busca la efectividad de los derechos fundamentales en toda la población, sin discriminación, que no recae solamente la obligación de ayuda y socorro mutuo en el Estado, sino también en la sociedad, la familia y las personas. El artículo 48 y 49 de la Ley Fundamental reitera el carácter principista de la solidaridad al señalar cómo la seguridad social es un servicio público de carácter obligatorio e irrenunciable, que se debe garantizar a todos los habitantes una real cobertura de protección implicando un mayor aporte de las personas que tiene capacidad de pago para subsidiar a aquellos que no lo tienen y de esta forma se materializa el principio de solidaridad. Por último, el artículo 95, numeral segundo de la Constitución Política estatuye que es deber de toda la población "obrar conforme al principio de solidaridad social, respondiendo con acciones humanitarias ante situaciones que pongan en peligro la vida o la salud de las personas”.

Cuando el legislador expide la Ley 100 de 1993, por la cual se crea el Sistema de Seguridad Social Integral, busca proporcionar cobertura integral de las contingencias del hombre en salud, riesgos laborales y pensión con el fin de lograr bienestar de todos y define el principio de solidaridad como "la práctica de la mutua ayuda entre las personas, las generaciones, los sectores económicos, las regiones y las comunidades bajo el principio del más fuerte hacia el más débil” (Ley 100 de 1993, artículo 2, literal c). La Corte Constitucional ha señalado y reiterado en su control abstracto de constitucionalidad: 
(...) en materia de seguridad social, el principio de solidaridad implica que todos los partícipes de este sistema deben contribuir a su sostenibilidad, equidad y eficiencia, lo cual explica que sus miembros deban en general cotizar, no sólo para poder recibir los distintos beneficios, sino además para preservar el sistema en su conjunto.

(...) el Estado Social de Derecho, a diferencia del Estado Liberal Clásico, parte del supuesto según el cual la realización del interés colectivo presupone la existencia de mecanismos de redistribución de los ingresos, a fin de que los menos favorecidos tengan acceso a la satisfacción de las necesidades básicas, asociadas con la efectividad de los derechos fundamentales. Uno de estos mecanismos es la organización de los sistemas de seguridad social, que pretenden conseguir la satisfacción universal de las necesidades básicas de la población en materia de salud y de previsión de los riesgos de merma de la capacidad laboral por invalidez, vejez o muerte. El funcionamiento de tales sistemas sólo se hace posible gracias al esfuerzo mancomunado del Estado y los particulares, y mediante la implementación de medidas que hagan viable la redistribución de los ingresos disponibles para estos propósitos. (C-399, 2007)

Ahora bien, el principio de universalidad se articula de igual forma con los principios de eficiencia y solidaridad frente a las razones de reconocer y proteger la dignidad humana de toda la población. La universalidad es una expresión de reconocimiento de los derechos humanos ${ }^{6}$ como derechos de todos, describiendo entonces, cómo dicho principio tiene particular relevancia en materia de seguridad social con la dignidad humana de todos los habitantes del pueblo colombiano sin restricción o excepción, asumiendo entonces un carácter iusfundamental. De igual forma, el principio de universalidad se correlaciona con los valores establecidos en el preámbulo de la Carta Política de la vida, la convivencia, el trabajo, la justicia y la igualdad frente a la cobertura de las contingencias inherentes al trabajo a través de las prestaciones asistenciales y económicas como elemento integrador del concepto de seguridad social, con el objeto de alcanzar los fines del Estado Social de Derecho ${ }^{7}$.

6 Declaración Universal de los Derechos Humanos, 1948.

7 Constitución Política de Colombia. Artículo 2: Fines del Estado. 
El legislador define de igual forma el principio de universalidad como "la garantía de la protección para todas las personas, sin ninguna discriminación, en todas las etapas de la vida" (Ley 100 de 1993, artículo 2, literal b). Ahora bien, el precedente de la Corte Constitucional define la universalidad como el principio que "hace relación a que todas las personas, sin discriminación alguna, tienen derecho a acceder a la seguridad social y que el Estado es responsable de garantizar que las entidades de la seguridad social, ya sean públicas o particulares, estén dispuestas en todo momento a brindar la atención que demanden los usuarios, en forma oportuna y eficaz" (C-739, 2002).

La deconstrucción del derecho y seguridad social en la economía informal: El problema de los trabajadores que se ubican en la economía informal es uno de los más serios problemas que enfrenta el territorio colombiano y países emergentes, por ser una realidad endógena y exógena que genera situaciones de injusticia e inequidad social, descritas y denunciadas en los reportes de la Organización de Naciones Unidas (ONU). Esta entidad presenta un panorama poco alentador de la situación económica de Colombia en el año 2011, al determina a Colombia como el tercer Estado más desigual en el mundo, después de Haití y Angola (Organización de Naciones Unidas, 2011). El Banco Mundial (BM) presenta un informe sobre las economías mundiales donde describe cómo Colombia es el segundo país más desigual en América Latina y el séptimo en todo el mundo (Banco Mundial, 2017). Afirma que el Estado colombiano ha disminuido los índices de pobreza, pero ha aumentado la brecha de desigualdad, porque el acceso a servicios públicos básicos sigue siendo mínimo, las riquezas y acumulación de tierras sigue en manos de un pequeño grupo y, por ende, se refleja una situación de condiciones no dignas en la mayoría de la población. Asimismo, la Comisión Económica para América Latina (CEPAL) presenta su informe anual 2017, con los mismos resultados al del Banco Mundial, al declarar cómo Colombia es el segundo país más desigual 
en la distribución del ingreso en la región (Comisión Económica para América Latina, 2018). En los informes de la CEPAL describen cómo Colombia es uno de los países con mayor índice de pobreza, indigencia, desempleo y desigualdad en la distribución de ingresos, bienes y tierras de la región, pero incongruente y paradójico por el aparente logro del expresidente Santos, quien incluye a Colombia en la Organización para la Cooperación y Desarrollo Económico (OCDE) (Cancilleria de Colombia, 2018).

El trabajo informal sigue siendo un fenómeno socio jurídico y económico, el cual refleja condiciones laborales precarias que vulneran derechos básicos e irrenunciables, bajo la mirada estática del Estado. El problema jurídico de la informalidad es complejo desde diversas miradas, como, por ejemplo, en el campo de la globalización, política neoliberal, consecuencia de la flexibilización laboral, evasión de responsabilidades tributarias, políticas públicas excluyentes, política utilitarista y pragmática de desarrollo económico, desregularización normativa en materia contractual, entre otros. Estos ejemplos son el reflejo de la trascendencia del fenómeno de la informalidad, que no debe ser abordado como un simple problema endógeno parroquial y consecuente mutismo jurídico del ordenamiento jurídico colombiano sobre las garantías laborales y cobertura en el sistema general de seguridad social integral en salud, riesgos laborales y pensión.

Llama la atención los reportes que presenta el Estado a través del Departamento Administrativo Nacional de Estadística (DANE) al analizar el empleo informal y la seguridad social frente a la cobertura en salud y pensión, excluyendo los riesgos laborales, desvelando una incongruencia y presunta omisión del Estado Social de Derecho en el cumplimiento de sus principios constitucionales y legales de efectividad, solidaridad y universalidad del sistema, porque se desvela cómo el promedio de los último cinco años, más de la mitad de afiliados al Sistema General de Seguridad Social en Salud pertene- 
cen al régimen subsidiado, por no contar con los recursos necesarios para ubicarse en el régimen contributivo (Departamento Nacional de Planeación, 2020).

\begin{tabular}{|l|l|l|l|l|}
\hline \multicolumn{5}{|c|}{ Afiliados al régimen contributivo y subsidiado } \\
\hline & \multicolumn{3}{|c|}{ Régimen contributivo } & Régimen subsidiado \\
\hline Mes y año & Beneficiario & Cotizantes & Total & Total \\
\hline $06 / 2016$ & 9907009 & 11867478 & 21774487 & 22555533 \\
\hline $12 / 2016$ & 9987926 & 12211278 & 22199204 & 22171457 \\
\hline $06 / 2017$ & 9795598 & 12053123 & 21848721 & 22144261 \\
\hline $12 / 2017$ & 9802996 & 12242458 & 22045454 & 22434572 \\
\hline $06 / 2018$ & 9789848 & 12309845 & 22099693 & 22559716 \\
\hline $12 / 2018$ & 9820262 & 12552678 & 22372940 & 22658095 \\
\hline $06 / 2019$ & 9909581 & 12717526 & 22627107 & 22852678 \\
\hline $12 / 2019$ & 9936312 & 12973367 & 22909679 & 22808919 \\
\hline $06 / 2020$ & 9683070 & 12382632 & 22065702 & 24307621 \\
\hline
\end{tabular}

Fuente: Se obtiene del análisis del sistema de seguridad social integral que reporta el Departamento Nacional de Planeación (DNP) sobre el Sistema General de Seguridad Social en Salud.

De igual forma, en el Sistema General de Pensiones, que está regulado por la Ley 100 de 1993 y constituido por dos regímenes, como lo son el Régimen de Prima Media y el Régimen de Ahorro Individual con Solidaridad, se refleja un significativo número del sector productivo y laboral colombiano que se encuentran afiliados en alguno de los dos regímenes, pero con un alto índice de personas inactivas, es decir, que están afiliadas sin realizar los debidos aportes periódicos al Sistema General de Pensiones, donde el mayor número de afiliados se ubican en el Régimen de Ahorro Individual con Solidaridad, duplicando el número de personas afiliadas al Régimen de Prima Media, que para el mes de mayo de 2020 representa una población total de 23568279 de personas afiliadas y de este núme- 
ro solamente aportan activamente 10986736 (Departamento de Planeación Nacional, 2020).

\begin{tabular}{|c|c|c|c|c|c|c|c|}
\hline \multicolumn{8}{|c|}{ Régimen de Prima Media y Régimen de Ahorro Individual con Solidaridad } \\
\hline \multirow[b]{2}{*}{ Mes y año } & \multicolumn{3}{|c|}{ Régimen de Prima Media } & \multicolumn{4}{|c|}{ Régimen de Ahorro Individual con Solidaridad } \\
\hline & Activos & Inactivos & $\begin{array}{l}\text { Subtotal } \\
\text { afiliados }\end{array}$ & Activos & Inactivos & $\begin{array}{l}\text { Subtotal } \\
\text { afiliados }\end{array}$ & Total afiliados \\
\hline 06/2016 & 2730937 & 3679063 & 6410000 & 7491502 & 6182283 & 13673785 & 20085380 \\
\hline $12 / 2016$ & 2818265 & 3618616 & 6436881 & 7494274 & 6621123 & 14115397 & 20554265 \\
\hline 06/2017 & 2903378 & 3600097 & 6503475 & 7675055 & 6830846 & 14505901 & 21011364 \\
\hline $12 / 2017$ & 2987868 & 3539325 & 6527193 & 7643915 & 7197741 & 14841656 & 21370750 \\
\hline 06/2018 & 3075522 & 3524139 & 6599661 & 7805477 & 7373268 & 15178745 & 21780247 \\
\hline $12 / 2018$ & 3183517 & 3519032 & 6702549 & 7807 & 7747603 & 15554616 & 22258911 \\
\hline 06/2019 & 3319433 & 3475712 & 6795145 & 7651421 & 8350561 & 16001982 & 22798778 \\
\hline $12 / 2019$ & 3084939 & 3785425 & 6870364 & 7683289 & 8779800 & 16463089 & 23335070 \\
\hline $05 / 2020$ & 3089551 & 3764854 & 6854405 & 7897185 & 8815136 & 16712321 & 23568279 \\
\hline
\end{tabular}

Fuente: Se obtiene del análisis del sistema de seguridad social integral que reporta el Departamento Nacional de Planeación (DNP) sobre el Sistema General de Pensiones.

La realidad de la informalidad puede ser analizada desde diferentes aristas, pero la verdadera distinción entre trabajo formal y trabajo informal radica en el cumplimiento de estándares básicos de principios laborales y de seguridad social expresos en la Carta Política (Constitución Política de Colombia, 1993, art. 53), el Código Sustantivo de Trabajo y demás normas que regulan las relaciones laborales, porque el sector informal es un fiel reflejo material de incumplimiento mínimo de derechos y garantías de trabajo y no cobertura al sistema general de seguridad social como cotizantes, quedando fuera del sistema por no gozar de una capacidad de pago en la mayoría de los casos. El compromiso y responsabilidad social del modelo de Estado escogido y asumido por el constituyente recae en todos, es decir, no solamente en los poderes públicos, sino también 
recae en la sociedad, familias y personas llamadas a apropiarse de los principios rectores de la seguridad social, expreso en su carácter trilemático principista de eficiencia, universalidad y solidaridad del sistema que se articulan entre sí, pero demanda una corresponsabilidad frente a la cobertura y aportes al sistema. El problema no está en la reubicación y entrega de subsidios e implementos de trabajo, sino en una real capacitación de vinculación al modelo de seguridad social a través de los aportes y cotización al sistema. Es hora de comprender que la protección concreta y efectiva del derecho laboral y seguridad social se expresa a través de la efectividad de los principios, tal como lo reitera y expresa la Corte Constitucional en su control abstracto:

4.1. La Constitución Política protege al trabajo como valor esencial y lo promueve en condiciones dignas y justas, fundada además en la solidaridad social. Esto implica que las relaciones laborales se aseguren con principios que restrinjan los abusos que pueden engendrarse al amparo de las leyes del mercado y del principio de la autonomía de la voluntad, o regulando las condiciones requeridas para racionalizar la economía con el fin, de asegurar el pleno empleo, también la distribución equitativa de oportunidades que tiene como efecto el mejoramiento de la calidad de vida de los trabajadores. (C-028, 2019)

Es hora de dejar la dialéctica de los imaginarios, los argumentos jurídicos utópicos cargados de falacia y decisiones pragmáticas que realmente no responden al caso concreto del fenómeno de la informalidad frente a la desprotección en materia de seguridad social por parte de las autoridades públicas, quienes reflejan una aparentes soluciones a través de la reubicación y capacitación (C-211, 2017), sin desconocer las posiciones loables de las administraciones distritales y municipales o entidades territoriales con una serie de ayudas para la población necesitada y marginada que se encuentran en la informalidad; por ejemplo, con la entrega de casetas, construcción de plazas de mercado, sanandresitos, paseos comerciales o cielos abiertos, implementación de políticas públicas de reemplazo de elementos de trabajo informal para incentivar el camino hacia la formalidad como ocurre con la sustitución de elementos rudimentarios y tradicionales 
de vehículos de tracción animal o carretillas por motos, cargueros o implementación de políticas asociativas de liderazgo, emprendimiento y trabajo colaborativo, como ocurre con el gremio de los recicladores a los que les brindan apoyo para asociarse y conformar cooperativas de trabajo, sindicatos y agremiaciones, pero sin una verdadera formación en el campo laboral, e incentivos que motivaran a dejar el mundo de la informalidad. Todas estas personas que recibieron los beneficios estatales siguen ajenos al sistema de seguridad social porque no reconocen los beneficios y ventajas que brinda el sistema al mantenerse como cotizantes del mismo, donde hace falta, de igual forma, el compromiso social de la población informal que se mantiene ajena al sistema de seguridad social integral de salud, riesgos y pensión.

El fenómeno de la informalidad, es decir, de la economía informal, es tan que no se resuelve con una simple norma o formalismo jurídico que pueda ser de carácter restrictivo y sancionatorio o con un enfoque paternalista, como ocurrió con los motos cargueros con la entrega de un nuevo medio de trabajo motorizado, en la mayoría de los casos no se aprovecharon todos los recursos ni mucho menos se sacó a esta parte de la población de la marginación social y estado de vulnerabilidad ni mucho menos se brindó una serie de garantías mínimas constitucionales y legales de cobertura al sistema general de seguridad social integral; de ahí que el contexto jurídico radica en la forma como la dignidad humana se debe reconocer, esto es, como principio rector del Estado Social de Derecho, llamado a brindar una especial protección a los más vulnerados por su condición de debilidad manifiesta.

De acuerdo con Arenas Monsalve (Arenas, 2011), en el análisis del precedente constitucional se determina cómo el sistema de seguridad social es un derecho universal, exigible, irrenunciable y de rango constitucional, con atribuciones propias y conexas con la misma vida y dignidad humana, aunque se ubique en la constitución 
de 1991, dentro de los derechos económicos, sociales y culturales (DESC). No se pueden desconocer, de igual forma, que los derechos sociales buscan satisfacer las categorías mínimas de existencia material y digna de la población. La realidad de los informales no se contextualiza con lo preceptuado por el mismo ordenamiento jurídico colombiano, porque el sistema económico imperante es excluyente. Las políticas públicas de inclusión social no pueden seguir con el mismo planteamiento del principio francés "laissez faire et laissez passer" porque se deshumaniza el derecho, principio y valor del trabajo y se reducen a las personas a simples objetos de producción o mercancía, ni mucho menos por posiciones de política pública utilitarias y neoliberales, que promueven un Estado mínimo que promueve la precarización, tercerización y desprotección de garantías y derechos mínimos laborales y de la seguridad social, ajenos al verdadero espíritu del poder constituyente reflejado en la Constitución del 91, que pasa de un Estado de legalidad a un Estado garantista y protector de derechos individuales y colectivos.

La OIT al pronunciarse sobre el trabajo decente y la economía informal describe cómo esta economía requiere de un proceso legal que involucre a todos los trabajadores y empresas informales para garantizar derechos y protección a la población excluida. Como razón fundante de la OIT está el reconocimiento de políticas públicas por parte de los Estados partícipes de la organización para construir una reforma legal en seguridad social y así cumplir con los principios rectores y fundantes de la organización (Conferencia Internacional del Trabajo, 2002). Lo anterior demanda un verdadero análisis del fenómeno de la informalidad que sea coherente con las políticas públicas internas y de gobernanza internacional conexas a los planteamientos normativos de índole internacional como ocurre con los objetivos de desarrollo sostenibles (ODS) implementados por la OIT desde el año 2015 para el año 2030 (OIT, 2015). 
La simple reubicación de los informales o sustitución de sus elementos de trabajo no responde ni ahonda el trascendental problema socio-jurídico del trabajo informal, que mantiene excluido a un gran sector de la población laboral en Colombia. Por esto se requiere una verdadera deconstrucción del derecho laboral y de la seguridad social en defensa de la dignidad humana, protegida y reconocida en los principios rectores de la seguridad social a través de la eficiencia, universalidad y solidaridad, que parten del modelo predominante de Estado Social de Derecho y de esta forma alcanzar la materialización de los fines teleológicos y deontológico del derecho en el campo laboral y seguridad social.

\section{Conclusiones}

La realidad colombiana no es ajena al proceso de globalización que genera paradigmas, retos y situaciones que no se regulan con la tradicional corriente normativa o formalismo jurídico, como ocurre con el problema de la informalidad, al no responder a las realidades coyunturales y problemas socio-jurídicos, siendo entonces los principios directrices que ayudan a establecer condiciones dignas y justas en el modelo de Estado Social de Derecho, en el que el trabajo y la seguridad social constituyen los principios fundantes que debe ser garantizados por el Estado. El nuevo concepto de Estado Social de Derecho demanda un compromiso social y efectivo de sus fines, donde la seguridad social no solamente es un derecho fundamental e irrenunciable, sino también constituye un factor determinante en la organización social como principio axiológico y deontológico expreso en la Constitución.

Son fines sociales del Estado el bienestar general de todos, el mejoramiento de la calidad de vida de la población y satisfacción de las necesidades básicas de los habitantes del territorio colombiano, constituyendo el eje temático del modelo Social Democrático de Derecho. 
El derecho debe responder a cada uno de los problemas suscitados en el devenir histórico de manera integral dentro del ordenamiento jurídico sin desconocer al hombre como sujeto del derecho; en el caso concreto, se deben argumentar políticas públicas de inclusión, articulación y reconocimiento de derechos mínimos e irrenunciables de toda la población, especialmente de aquella parte de la población que se mantiene excluidas de derechos básicos y mínimos laborales y de la seguridad social, como ocurre con el sector informal.

El Estado colombiano no puede aminorar derechos inalienables con argumentos de posiciones mayoritarias o económicas expresas en modelos jurídicos utilitaristas o pragmáticos, en detrimento de las garantías fundamentales de la población, como es el caso en la cobertura al sistema de seguridad social. Al contrario, hay que tener una atención especial con los grupos minoritarios y que se encuentran en una situación de debilidad manifiesta, es decir, quienes requieren de atención constitucional; por esto surge la necesidad de deconstruir el derecho retomando su valor deontológico o principista para alcanzar la connotación de universalidad, eficiencia y solidaridad, con un carácter de orden público y vinculante dentro del ordenamiento jurídico a través de la aplicación de los principios como directrices.

El fenómeno jurídico de la informalidad responde a un problema endógeno y exógeno, fruto y consecuente de la globalización y flexibilización laboral que exigen respuestas concretas y claras frente a los derechos laborales y de la seguridad social a través de la cotización al sistema para el reconocimiento de todos los beneficios de las prestaciones asistenciales y económicas que brinda la estructura de la ley 100 de 1993 y de esta forma garantizar derechos inherentes a la condición humana. 
Los principios se presentan bajo la estructura de la argumentación jurídica que no se reduce a una simple discrecionalidad o decisión caprichosa de las autoridades públicas que aplican el derecho frente a los conflictos sociales y laborales. Son los principios los que responden a los casos concretos actuales como núcleo problemático de la realidad, que sobre el fenómeno de estudio, la informalidad, requiere una superación del formalismo jurídico a través del derecho como integridad para reconocer en las fuentes del derecho la protección y garantías mínimas de la persona y dignidad humana sin exclusión de derechos básicos, donde no solo la actividad laboral subordinada está protegida por el ordenamiento jurídico interno e internacional, sino todos aquellos derechos y principios inherentes al hombre frente al trabajo y dignidad.

Urge la necesidad de retomar la esencia del derecho en la deconstrucción de los principios constitucionales y legales que garantiza la protección y cobertura al sistema general de seguridad social integral de toda la población sin discriminación, como estrategia de formalización del empleo y equilibrio social en consonancia con las políticas públicas. El reconocimiento del derecho como integridad ayuda a asumir una política pública real y coherente con los pilares del Estado Social Democrático de Derecho.

La seguridad social es un compromiso y responsabilidad social de todos, que no solamente recae en los poderes públicos, sino también recae en la sociedad, familia y personas llamadas a apropiarse de los principios rectores de la seguridad social, expreso en el carácter trilemático principista de eficiencia, universalidad y solidaridad, aclarando que el problema no está en la reubicación y entrega de subsidios e implementos de trabajo, sino en la plena materialización de cobertura al sistema de seguridad social integral expresa en salud, riesgos y pensión a través de los aportes y cotización de todos. 


\section{Referencias}

Alexy, R. (2002). Teoría de los derechos fundamentales. Madrid, España: Centro de Estudios Políticos y Constitucionales.

Arango, A. (8 de Mayo de 2019). Mintrabajo celebró aprobación de artículos dentro PND que promueven trabajo decente. (W. Radio, Entrevistador). Recuperado de https://www. wradio.com.co/noticias/actualidad/mintrabajo-celebro-aprobacion-de-articulos-dentro-del-pnd-que-promueven-trabajo-decente/20190508/nota/3900261.aspx

Arenas, G. (2011). El derecho colombiano de la seguridad social. Bogotá: Legis.

Banco Mundial. (2017). Reporte de las Economías Mundiales. Washington, D. C.: Banco Mundial.

Bernal, C. (2006). Metodología de la Investigación. México: Pearson Educación.

Bonorino, P., \& Peña, J. (2006). Filosofía del Derecho. Bogotá: Consejo Superior de la Judicatura.

C-028 (Corte Constitucional 30 de Enero de 2019). Recuperado de https://www.funcionpublica.gov.co/eva/gestornormativo/norma.php? $\mathrm{i}=91280$

C-1041 (Corte Constitucional 4 de Diciembre de 2007). Recuperado de https://www.corteconstitucional.gov.co/relatoria/2007/C-1041-07.htm\#_ftnref18

C-211 (Corte Consitucional 5 de Abril de 2017). Recuperado de https://www.corteconstitucional.gov.co/relatoria/2017/C-211-17.htm

C-211 (Corte Constitucional 5 de Abril de 2017). Recuperado de https://www.corteconstitucional.gov.co/relatoria/2017/C-211-17.htm

C-211, C-211 de 2017 (Corte Constitucional 5 de Abril de 2017). Recuperado de https:// www.corteconstitucional.gov.co/relatoria/2017/C-211-17.htm

C-399 (Corte Constitucional 23 de Mayo de 2007). Recuperado de https://docs.supersalud. gov.co/PortalWeb/Juridica/Sentencias/SC399_07.pdf

C-438, C-438 de 2013 (Corte Constitucional 10 de Julio de 2013).

C-450 (Corte Constitucional 4 de Octubre de 1995). Recuperado de https://www.corteconstitucional.gov.co/relatoria/1995/C-450-95.htm 
C-739 (Corte Constitucional 10 de Septiembre de 2002). Recuperado de https://www.funcionpublica.gov.co/eva/gestornormativo/norma.php? $i=6246$

Cabrera, L. (2018). El significado real de que Colombia sea un Estado Social de Derecho. Dixi, 20(27), 1-15. Recuperado de https://revistas.ucc.edu.co/index.php/di/article/ view/2390/2420

Cancilleria de Colombia. (25 de Mayo de 2018). Presidente Santos anunció el ingreso de Colombia a la OCDE. Bogotá: Cancilleria de Colombia. Recuperado de https://www. cancilleria.gov.co/en/newsroom/news/presidente-santos-anuncio-ingreso-colombiaocde

Carrillo, F. (4 de Febrero de 2020). "A la calle hay que oírla": las críticas del Procurador a varias iniciativas del Gobierno. (N. Caracol, Entrevistador) Recuperado de https:// noticias.caracoltv.com/politica/la-calle-hay-que-oirla-las-criticas-del-procuradorvarias-iniciativas-del-gobierno

Centro de Investigaciones Socio Jurídicas. (2004). Guía para la elaboración de proyectos de investigación en derecho. Bogotá: Universidad Libre. Recuperado de https://davidinvestigador.es.t//GUIA-INVESTIGACION-UNILIBE.htm

Comisión Económica para América Latina. (2018). Economías de América Latina y el Caribe. Santiago de Chile: Publicación de las Naciones Unidas.

Conferencia Internacional del Trabajo -0IT-. (2002). Trabajo decente y la economía informal . Ginebra: Oficina Internacional del Trabajo.

Congreso de la República de Colombia. (23 de Diciembre de 1993). Ley 100. Crea el sistema de seguridad social integral. Bogotá, Cundinamarca, Colombia: Gaceta.

Congreso de la República de Colombia. (23 de Diciembre de 1993). Ley 100 de 1993. Seguridad social en Colombia. Bogotá, Cundinamarca, Colombia: La Gaceta.

Congreso de la República de Colombia. (23 de Diciembre de 1993. Art. 2). Ley 100. Crea el sistema de seguridad social integral. Bogotá, Cundinamarca, Colombia: Gaceta.

Congreso de la República de Colombia. (29 de Julio de 2016). Ley 1801. Código Nacional de Policía y Convivencia. Bogota, Cundinamarca, Colombia: Gaceta.

Congreso de la República de Colombia. (2019). Plan Nacional de Desarrollo. Bogotá: Gaceta. Recuperado de https://colaboracion.dnp.gov.co/CDT/Prensa/PND-2018-2022.pdf

Constitución Política de Colombia. (1991). Bogotá: Gaceta. Recuperado de http://www.secretariasenado.gov.co/senado/basedoc/constitucion_politica_1991.html 
Cruz, J. (2006). Los métodos para los juristas. En C. Courtis (coord.), Observar la ley: ensayos sobre metodología de la investigación jurídica (pp.17-40). Madrid: Trotta

DANE. (17 de abril de 2019). DANE Información Estratégica. Bogotá: DANE. Recuperado de DANE: https://www.dane.gov.co/files/investigaciones/boletines/ech/ech_informalidad/bol_ech_informalidad_sep19_nov19.pdf

DANE. (25 de 04 de 2019). Empleo informal y seguridad social. Bogotá: DANE. Recuperado de http://www.dane.gov.co/index.php/estadisticas-por-tema/mercado-laboral/ empleo-informal-y-seguridad-social

DANE. (2020). Boletín técnico: medición del empleo informal y de la seguridad social. Bogotá: DANE. Recuperado de https://www.dane.gov.co/files/investigaciones/boletines/ ech/ech_informalidad/bol_ech_informalidad_nov19_ene20.pdf

Departamento de Planeación Nacional. (2020). Seguridad social integral. Afiliados a pensiones. Bogotá: DNP. Recuperado de https://www.dnp.gov.co/programas/desarrollo-social/subdireccion-de-empleo-y-seguridad-social/Paginas/Seguridad-Social-Integral. aspx

Derrida, J. (1989). La escritura y la diferencia. Barcelona: Anthropos.

Derrida, J. (1993). La voix et le phenomene. Paris: Quadrige.

Duque, I. (6 de Febrero de 2020). "Hay muchas personas que trabajan por horas": Duque sobre polémica propuesta de la Ministra Arango. (R. Bayona, Entrevistador) Recuperado de https://noticias.caracoltv.com/politica/hay-muchas-personas-que-trabajanpor-horas-duque-sobre-polemica-propuesta-de-la-ministra-arango

Dworkin, R. (1984). Derecho en serio. Barcelona: Ariel.

Dworkin, R. (1989). Los derechos en serio. Barcelona: Ariel.

Dworkin, R. (2007). La justicia con toga. Madrid: Marcial Pons.

Dworkin, R. (2012). El imperio de la justicia. Barcelona: Gedisa.

FMI . (2019). Informe anual del FMI 2019. Washintong: FMI. Recuperado de https://www. imf.org/external/pubs/ft/ar/2019/eng/assets/pdf/imf-annual-report-2019-es.pdf

Hart, H. (1998). El concepto de derecho. Buenos Aires: Abeledo Perrot.

Heidegger, M. (1993). El ser y el tiempo. Mexico: Fondo de Cultura Económica. 
Hernández, R., y otros. (1997). Metodología de la Investigación. Bogotá: Panamericana Formas e Impresos S.A.

Kant, E. (1921). Fundamentos de la metafísica de las costumbres . Madrid: Pedro M. Rosario Barbosa.

Marx, K. (1844). Manuscritos económicos y filofóficos de 1844. Biblioteca Universal. Recuperado de https://www.biblioteca.org.ar/libros/157836.pdf

OIT.A (2015). Objetivos de Desarrollo Sostenible. Ginebra: OIT. Recuperado de https://www. ilo.org/global/topics/sdg-2030/lang--es/index.htm

OIT.B (2015). Recomendación sobre la transición de la economía informal a la economía formal. Ginebra: OIT. Recuperado de https://www.ilo.org/wcmsp5/groups/public/--ed_norm/---relconf/documents/meetingdocument/wcms_379098.pdf

OIT. (2016). Estudios sobre el crecimiento con equidad. Ginebra: OIT.

OIT. (2019). Dirigentes del mundo hacen un llamado a la acción por el futuro del trabajo. Ginebra: OIT. Recuperado de https://ilo.cetc.stream/2019/06/19/address-by-h-e-mrivan-duque-marquez-president-of-the-republic-of-colombia/

Olvera, J. (2015). Metodología de la Investigación Jurídica. Mexico: Universidad Autónoma del Estado de México.

ONU. (1948). La declaración universal de los derechos humanos. París: ONU. Recuperado de https://www.un.org/es/universal-declaration-humanrights/\#: :text=Art\%C3\%ADculo\%201.,los\%20unos\%20con\%20los\%20otros.

Organización de Naciones Unidas. (2011). Colombia rural: razones para la esperanza. Informe Desarrollo Humano Colombia. New York: Programa de Naciones Unidas para el Desarrollo (PNUD).

Rodriguez, A. P. (1998). Los Principios del Derecho del Trabajo. Buenos Aires: Depalma.

Salazar-Xirinachs, J., y Chacaltana, J. (2018). Políticas de formalización en América Latina. Avances y desafios. Lima: OIT. Recuperado de https://www.ilo.org/wcmsp5/groups/ public/---americas/---ro-lima/documents/publication/wcms_645159.pdf

SU 049, SU 049 de 2017 (Corte Constitucional 2 de Febrero de 2017). Recuperado de https://www.corteconstitucional.gov.co/relatoria/2017/SU049-17.htm

T-039 (Corte Constitucional 30 de Enero de 2017). 
T-067 (Corte Constitucional 3 de Febrero de 2017). Recuperado de https://www.corteconstitucional.gov.co/relatoria/2017/T-067-17.htm

T-085 de 2012 (Corte Constitucional 19 de Febrero de 2012).

T-406 (Corte Constitucional 5 de Junio de 1992). Recuperado de https://www.corteconstitucional.gov.co/relatoria/1992/T-406-92.htm 